\section{POS0506 TENOSYNOVITIS HAS A HIGH SENSITIVITY FOR EARLY ACPA-POSITIVE AND ACPA-NEGATIVE RA: A LARGE CROSS-SECTIONAL MRI STUDY}

X. Matthijssen ${ }^{1}$, F. Wouters ${ }^{1}$, N. Sidhu ${ }^{1}$, E. Niemantsverdriet ${ }^{1}$, A. van der Helm - van Mil ${ }^{1,2} .{ }^{1}$ Leiden University Medical Center (LUMC), Rheumatology, Leiden, Netherlands; ${ }^{2}$ Erasmus MC, Rheumatology, Rotterdam, Netherlands

Background: Clinically evident tenosynovitis can be seen in established Rheumatoid arthritis (RA). Imaging research has recently shown that tenosynovitis at small joints occurs in early RA, contributes to typical RA symptoms (including joint swelling) and is infrequent in healthy controls. Imaging-detectable tenosynovitis is often not recognizable at joint examination, hence its prevalence can therefore be underestimated. Objectives: We hypothesized that if MRI-detectable tenosynovitis is a true RA-feature, the sensitivity for RA is high, in both ACPA-positive and -negative RA, and lower in other diseases that are associated with enthesitis (such as Spondyloarthritis (SpA) and Psoriatic Arthritis (PsA)). So far, no large MRI-study addressed these questions. Methods: Consecutive early arthritis patients $(n=1211)$ from one health-care region underwent contrast-enhanced 1.5T MRI of hand and foot at diagnosis. MRIs were scored for synovitis and tenosynovitis by two readers blinded for clinical data. All included patients with ACPA-positive RA ( $n=250)$, ACPA-negative RA $(n=282)$, PsA $(n=88), S p A$ with peripheral arthritis $(n=24)$, reactive arthritis $(n=30)$ and self-limiting undifferentiated arthritis $(U A ; n=76)$ were studied. Sensitivity was calculated.

Results: The sensitivity of tenosynovitis in RA was $85 \% ; 88 \%$ for ACPA-positive RA and $82 \%$ for and ACPA-negative RA $(p=0.19)$. The sensitivity for RA was significantly higher than for PsA $(65 \% ; \mathrm{p}=0.001)$, SpA $(53 \% ; \mathrm{p}<0.001)$, reactive arthritis $(36 \% ; p<0.001)$ and self-limiting UA $(42 \% ; p<0.001)$. The observed sensitivity of MRI-synovitis was $91 \%$ in RA and ranged $83-54 \%$ in the other groups. Conclusion: MRI-detected tenosynovitis has a high sensitivity for early ACPA-positive and ACPA-negative RA. This supports both juxta-articular (tenosynovitis) and intra-articular synovial involvement is characteristic for RA.

Rheumatoid arthritis

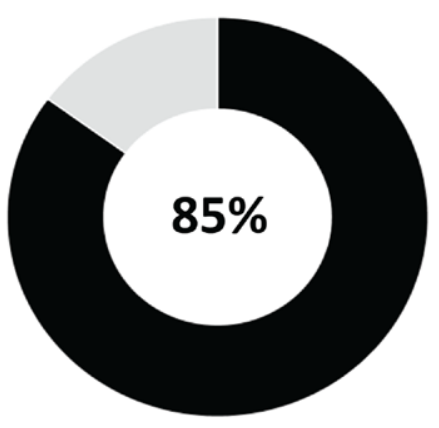

ACPA-positive RA

ACPA-negative RA
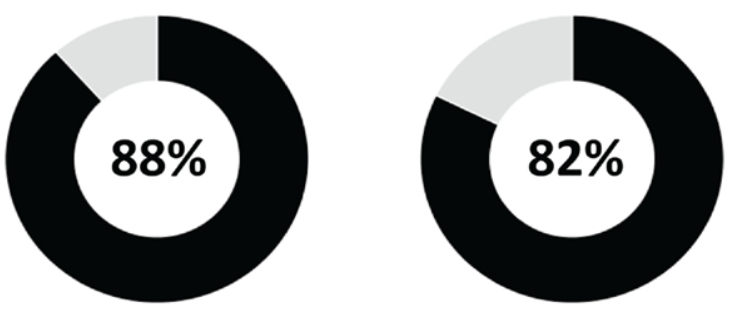

Psoriatic arthritis Spondyloarthritis Reactive arthritis Self-limiting UA
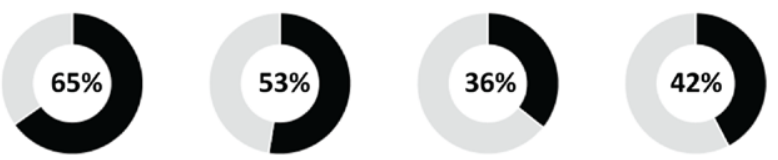

Figure 1. Presence of tenosynovitis (in black) in wrist MCPs and MTPs, in rheumatoid arthritis, stratified for ACPA-status and compared to other diseasesLegend: RA: Rheumatoïd arthritis; ACPA: anti-citrullinated protein antibodies; UA: undifferentiated arthritis

Disclosure of Interests: None declared DOI: 10.1136/annrheumdis-2021-eular.180

\section{\begin{tabular}{|l|l|l|}
\hline POS0507 UNUSUALY HIGH PREVALENCE OF ATRIAL \\
\hline
\end{tabular} FIBRILLATION IN PATIENTS WITH RHEUMATOID ARTHRITIS}

B. Mukerii ${ }^{1}, \mathrm{~F}$. Wang $^{1}$, R. Markert ${ }^{2}$, V. Mukerji ${ }^{3} .{ }^{1}$ Dayton Veteran Administration Medical Center, Rheumatology, Dayton, United States of America; ${ }^{2}$ Wright State University, Medicine, Dayton, United States of America; ${ }^{3}$ Dayton Veteran Administration Medical Center, Cardiology, Dayton, United States of America

Background: In rheumatoid arthritis, circulating autoantibodies like anticyclic citrullinated peptides and rheumatoid factor may be present for years prior to symptom onset. In RA, there are high levels of circulating tumor necrosis factors, interleukins, matrix metalloproteinases, growth factors, and adhesion molecules that cause tissue damage $e^{1,2}$. This can affect different organs in different ways. It is possible that in the heart, they cause inflammation of cardiac tissue ${ }^{3,4}$.

Objectives: This study was conducted to determine if patients with RA, an inflammatory arthritis, and osteoarthritis (OA), a degenerative arthritis, differ in the prevalence of cardiac arrhythmias.

Methods: This was a retrospective study. We enrolled 300 consecutive patients, 150 with RA and 150 with OA. Patients were assessed for age, race, gender, body mass index (BMI), smoking status, hypertension (HTN), hyperlipidemia (HLD), diabetes mellitus (DM), cardiovascular disease (CVD), coronary artery disease (CAD), cardiac arrhythmias including conduction abnormalities, cerebrovascular accident (CVA), congestive heart failure (CHF), abdominal aortic aneurysm (AAA), pulmonary embolism (PE), deep vein thrombosis (DVT), and peripheral vascular disease (PVD). RA and OA groups were compared with the chi square test and the Mann-Whitney test.

Results: The RA and OA groups did not differ on the demographic characteristics of age or race. The presence of DM was similar in the two groups. The RA group had more women than the OA group (12.7\% vs. $5.3 \%, p=0.026)$. The OA group had a higher mean BMI (33.1 vs 30.0, $\mathrm{p}<0.001)$ and higher prevalence of HLD $(78.9 \%$ vs $64.6 \%, p=0.007)$ and HTN $(79.3 \%$ vs. $66.7 \%, p=0.013)$. RA patients had a higher rate of smoking $(70.0 \%$ vs $56.7 \%, p=0.017)$ and longer duration of smoking (34.3 years vs. 28.2 years, $p=0.003$ ). The RA group had a higher prevalence of CVD (58.7\% vs. $42.7 \%, p=0.006)$. Further data analysis among CVD showed there was no difference between the two groups for the prevalence of CAD, CHF, CVA, AAA, PVD or DVT/PE. RA patients had a higher prevalence of cardiac arrhythmias (31.3\% vs. $12.0 \%, p<0.001$ ). Among all types of cardiac arrhythmias, no significant difference was found between two groups for the prevalence of supraventricular tachycardia ventricular arrhythmias, or conduction abnormalities. Patients with RA had a significantly higher prevalence of atrial fibrillation ( $15.3 \%$ vs. $6.0 \%, p=0.015)$

Conclusion: Cardiac arrhythmias occur more frequently in RA patients than in OA patients. Among all the arrhythmias, atrial fibrillation has a significantly higher prevalence in RA patients.

\section{REFERENCES:}

[1] Maradit-Kremers $\mathrm{H}$, et al. Increased unrecognized coronary heart disease and sudden deaths in rheumatoid arthritis: A population-based cohort study. Arthritis Rheum. 2005; 52: 402-411

[2] Seferovic PM, et al. Cardiac arrhythmias and conduction disturbances in autoimmune rheumatic diseases. Rheumatology. 2006; 45: 39-42

[3] Avina-Zubiets JA, et al. Risk of incident cardiovascular events in patients with rheumatoid arthritis: A met-analysis of observational studies. Ann Rheum Dis 2012; 71: 1524-1529

[4] Lazzerini PE, Capechi L, et al. Systemic Inflammation and arrhythmic risk: Lessons from rheumatoid arthritis. European Heart Journal. 2017; 38: 1717-1727

Disclosure of Interests: None declared

DOI: 10.1136/annrheumdis-2021-eular.243

\section{POS0508 EVALUATION OF RESPONSE TO PNEUMOCOCCAL VACCINATION IN PATIENTS WITH RHEUMATOID ARTHRITIS RECEIVING UPADACITINIB: RESULTS FROM A PHASE 2 OPEN-LABEL EXTENSION STUDY}

K. Winthrop $^{1}$, J. Ignacio Vargas ${ }^{2}$, E. Drescher ${ }^{3}$, C. Garcia Garcia ${ }^{4}$, A. Friedman ${ }^{5}$, J. Enejosa ${ }^{5}$, N. Khan ${ }^{5}$, Y. Li ${ }^{5}$, J. Klaff ${ }^{5}$, A. Kivitz ${ }^{6}$. ${ }^{1}$ Oregon Health \& Science University, Infectious Disease, Portland, United States of America; ${ }^{2}$ Quantum Research, Medicine, Puerto Varas, Chile; ${ }^{3}$ Veszprém Csolnoky, Ferenc County Hospital, Veszprém, Hungary; ${ }^{4}$ Hospital General de México, "Dr. Eduardo Liceaga", Mexico City, Mexico; ${ }^{5}$ AbbVie Inc., Rheumatology, North Chicago, United States of America; ${ }^{6}$ Altoona Center, Clinical Research, Duncansville, United States of America

Background: Pneumococcal vaccination is recommended in patients with RA who are receiving conventional synthetic/biologic DMARDs. ${ }^{1}$ Upadacitinib (UPA) is an oral Janus kinase (JAK) inhibitor engineered to have a greater selectivity for JAK1 versus JAK2, JAK3, and tyrosine kinase 2, and is approved for the treatment of RA. Objectives: The aim of this analysis was to assess the impact of long-term treatment with UPA + background MTX on immunologic responses to Prevnar $13 \AA$ (Pneumococcal 13-valent Conjugate Vaccine [Diphtheria CRM ${ }_{197}$ Protein]; 
PCV13) in patients with RA enrolled in the ongoing Phase 2 open-label extension study BALANCE-EXTEND.

Methods: Patients from BALANCE-EXTEND receiving PCV13 vaccination were required to be on UPA $15 \mathrm{mg}$ once daily (QD) or $30 \mathrm{mg}$ QD and background MTX for $\geq 4$ weeks prior to, and after, PCV13 vaccination; MTX was not interrupted prior to vaccination. Vaccination antibody titers were collected pre-vaccination (Week 0) and post-vaccination (Weeks 4 and 12). The primary variable was the proportion of patients with satisfactory humoral response to PCV13 ( $\geq 2$-fold increase in antibody concentration from pre-vaccination [Week 0 ] in $\geq 6 / 12$ pneumococcal antigens [1, 3, 4, 5, 6B, 7F, 9V, 14, 18C, 19A, 19F, and 23F]) at 4 weeks post-vaccination

Results: Of 111 patients (UPA $15 \mathrm{mg}, \mathrm{n}=87$; UPA $30 \mathrm{mg}, \mathrm{n}=24$ ), $86 \%$ were female most $(98 \%)$ were white, and mean (standard deviation) age was 58.4 (12.0) years. Prior to vaccination, patients had a median (range) duration of RA of 9.3 (3.4-35.0) years and had been receiving UPA for a median (range) of 3.9 (3.0-4.9) years. All but 3 patients were taking concomitant MTX, and $44.1 \%$ were taking a CS (median daily dose, $5.0 \mathrm{mg}$ ). All 111 patients received PCV13, none discontinued UPA during the first 4 weeks, and blood samples were available from 83/23 and 79/22 patients in the UPA 15/30 mg groups at Weeks 4 and 12, respectively. At 4 weeks, satisfactory humoral response to PCV13 occurred in 67.5\% (95\% confidence interval [Cl]: $57.4-77.5)$ and $56.5 \%(95 \% \mathrm{Cl}: 36.3-76.8)$ of patients receiving UPA 15 and $30 \mathrm{mg}$, respectively. At 12 weeks, satisfactory humoral response to PCV13 occurred in $64.6 \%$ (95\% Cl:54.0-75.1) and 54.5\% (95\% Cl: 33.7-75.4) of patients receiving UPA 15 and $30 \mathrm{mg}$, respectively (Figure 1). There was no clear difference in response between patients receiving and not receiving concomitant CS. Within 30 days post-vaccination, 2 adverse events (AEs) were considered as possibly related to UPA (1 case of diverticulitis, UPA 15mg; 1 case of anemia, UPA $30 \mathrm{mg}$ ) and no serious AEs were reported (Table 1). Two patients experienced pyrexia and 1 subject each experienced vaccination-site pain and headache within 1 day post-vaccination (all in UPA 15mg group).

Table 1. Safety through 30 days post-PVC13 vaccination in UPA-treated patients

\begin{tabular}{lcc}
\hline Event, $\mathrm{n}(\%)$ & $\begin{array}{c}\text { UPA 15 mg QD } \\
(\mathrm{n}=87)\end{array}$ & $\begin{array}{c}\text { UPA 30 mg QD } \\
(\mathrm{n}=24)\end{array}$ \\
\hline Any AE & $15(17.2)$ & $3(12.5)$ \\
Serious AE & 0 & 0 \\
AE leading to discontinuation of study drug & 0 & 0 \\
AE with reasonable possibility of being related to UPA & $1(1.1)^{\mathrm{b}}$ & $1(4.2)^{\mathrm{c}}$ \\
Death & 0 & 0
\end{tabular}

${ }^{a}$ As assessed by the investigator. ${ }^{b}$ Diverticulitis. ${ }^{\mathrm{c}}$ Anemia.AE, adverse event: PVC13, Pneumococcal 13-valent Conjugate Vaccine [Diphtheria $\mathrm{CRM}_{197}$ Protein]; QD, once daily; UPA, upadacitinib.

Conclusion: Satisfactory humoral response to PCV13 at 4 weeks occurred in two-thirds of patients with RA receiving long-term treatment with UPA $15 \mathrm{mg}$ $\mathrm{QD}+$ background MTX. This is broadly consistent with pneumococcal vaccine humoral responses observed in patients with RA treated with other JAK inhibitors, biologics, or placebo. ${ }^{2-4}$

REFERENCES:

[1] Singh JA, et al. Arthritis Care Res 2016;68:1-25

[2] Winthrop KL, et al. Arthritis Res Ther 2019;21:102.

[3] Bingham CO, et al. Ann Rheum Dis 2015;74:818-22.

[4] Winthrop KL, et al. Ann Rheum Dis 2016;75:687-95.

Figure 1. Proportion $(\%, 95 \% \mathrm{Cl})$ of UPA-treated patients with satisfactory humoral response ${ }^{\mathrm{a}}$ to PVC13 at Weeks 4 and 12 (full analysis set)

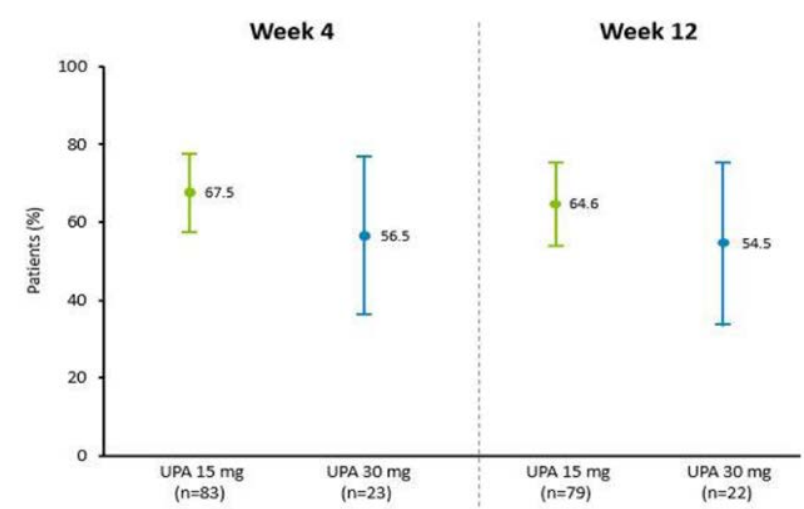

Satisfactory humoral response was defined as z2-fold increase in antibody concentration from the vaccination baseline in 26 out of 12 pneumococcal antigens $\left(1,3,4,5,6 \mathrm{~B}, 7 \mathrm{~F}, 9 \mathrm{~V}, 14,18 \mathrm{C}, 19 \mathrm{~A}, 19 \mathrm{~F}\right.$, and 23F). ${ }^{*}$ Number of patients based on availability of blood samples collected at Weeks 4 and 12 . CI, confidence interval; PVC13, Pneumococcal 13-valent Conjugate Vaccine [Diphtheria CRM 197 Protein]; UPA,
Acknowledgements: AbbVie funded this study and participated in the study design, research, analysis, data collection, interpretation of data, reviewing, and approval of the publication. All authors had access to relevant data and participated in the drafting, review, and approval of this publication. No honoraria or payments were made for authorship. Medical writing assistance was provided by Frances Smith, $\mathrm{PhD}$, of 2 the Nth, which was funded by AbbVie.

Disclosure of Interests: Kevin Winthrop Consultant of: AbbVie, Bristol-Myers Squibb, Eli Lilly, Galapagos, Gilead, Pfizer, Roche, and UCB., Grant/research support from: AbbVie, Bristol-Myers Squibb, Eli Lilly, Galapagos, Gilead, Pfizer, Roche, and UCB., Juan Ignacio Vargas Consultant of: AbbVie, Bristol-Myers Squibb, Eli Lilly, Galapagos, Gilead, Pfizer, Roche, and UCB, Grant/research support from: AbbVie, Bristol-Myers Squibb, Eli Lilly, Galapagos, Gilead, Pfizer Roche, and UCB, Edit Drescher: None declared, CONRADO GARCIA GARCIA: None declared, Alan Friedman Shareholder of: AbbVie, Employee of: AbbVie, Jeffrey Enejosa Shareholder of: AbbVie, Employee of: AbbVie, Nasser Khan Shareholder of: AbbVie, Employee of: AbbVie, Yihan Li Shareholder of: AbbVie, Employee of: AbbVie, Justin Klaff Shareholder of: AbbVie, Employee of: AbbVie, Alan Kivitz Shareholder of: Amgen, Novartis, Gilead, GlaxoSmithKline, Pfizer Inc., and Sanofi, Speakers bureau: AbbVie, Celgene, Eli Lilly, Flexion, Genzyme, Horizon, Merck, Novartis, UCB, Pfizer Inc., Regeneron, Sanofi, and UCB, Consultant of: AbbVie, Boehringer Ingelheim, Genzyme, Gilead Janssen, Pfizer Inc., Regeneron, Sanofi, SUN Pharma Advanced Research, and UCB

DOI: 10.1136/annrheumdis-2021-eular.559

\section{POS0509 \\ PREVALENCE OF RHEUMATOID CACHEXIA AND ITS ASSOCIATION WITH SERUM FETUIN-A LEVELS IN CAUCASIAN PATIENTS WITH RHEUMATOID ARTHRITIS}

E. Papichev ${ }^{1}$, B. Zavodovsky ${ }^{1}$, L. Seewordova ${ }^{1}$, J. Polyakova ${ }^{1}$, Y. Akhverdyan ${ }^{1}$ ${ }^{1}$ FSBI "Research Institute of Clinical and Experimental Rheumatology n.a. A.B. Zborovsky", Treatment and Prevention of Joint Disease Laboratory, Volgograd, Russian Federation

Background: Rheumatoid cachexia is an under-recognized pathological condition, which is characterized by a loss of muscle strength and can be presented as a low fat-free mass and normal or high BMI in patients with rheumatoid arthritis determined by dual-energy X-ray absorptiometry (DEXA) [1]. Though fetuin-A is one of a major noncollagen proteins in bone tissue it is of interest to clarify its association with rheumatoid cachexia.

Objectives: To define the prevalence of rheumatoid cachexia in Caucasian patients with rheumatoid arthritis determined by DEXA method and to study the association of serum fetuin-A levels with body composition and rheumatoid cachexia in this group.

Methods: 110 Caucasian patients with rheumatoid arthritis undergone DEXA with «Total Body» program. All patients fulfilled the 2010 ACR/EULAR classification criteria for rheumatoid arthritis. The diagnosis of rheumatoid cachexia was based on Engvall I.L. criteria: fat-free mass index less than 10th percentile with fat mass index above 25th percentile [1]. We used values for these indexes from the study performed in 2008 by Coin A. et al. on Italian population due to a lack of standard values [2]. Fetuin-A in serum was determined by enzyme-linked immunosorbent assay. 72 patients have been taking glucocorticoids for more than 3 months in dose equivalent or higher than $5 \mathrm{mg}$ of prednisolone daily. Statistical analysis was performed using a software package "Statistica 12.0." Parametric data is presented as $\mathrm{M} \pm \mathrm{St}$.dev, and nonparametric as $\mathrm{Me}$ [Q1-Q3].

Results: Rheumatoid cachexia was diagnosed in 25 patients $(22,7 \%)$ with mean age of $52,2 \pm 8,14$ years. The prevalence of cachexia was the same in groups of patients who took glucocorticoids $(n=16,22,2 \%)$ and who didn't $(n=9,23,7 \% ; p=0,465)$. Median cumulative dose of oral glucocorticoids in patients with rheumatoid cachexia was higher but fell just short of statistical significance $(8,0[2,9-13,5]$ g vs $5,4[0,2-11,6] \mathrm{g} ; Z=-1,42 ; p=0,156)$. Median serum fetuin-A levels were only slightly significantly lower in patients with rheumatoid cachexia $(757,7[700,5-932,0] \mu \mathrm{g} / \mathrm{ml}$ vs $769,3[660,3-843,4]$ $\mu \mathrm{g} / \mathrm{ml} ; \mathrm{Z}=-1,35 ; \mathrm{p}=0,175)$. Positive statistically significant correlations were observed between serum fetuin-A levels and bone mass in right $(r=0,222, p$ $=0,027)$ and left $(r=0,263, p=0,008)$ lower limbs, trunk $(r=0,268, p=0,007)$, gynoid region $(r=0,293, p=0,003)$, both lower limbs $(r=0,246, p=0,014)$ and whole-body $(r=0,235, p=0,019)$.

Conclusion: Rheumatoid cachexia was diagnosed in $22,7 \%$ of patients with rheumatoid arthritis. No association was observed between glucocorticoids intake and rheumatoid cachexia, despite the expected influence of them on muscle mass. We may suggest that occurrence and pathogenesis of this condition is complex and should be studied more precisely. It is well-known that patients with such condition have a higher risk for metabolic syndrome, arterial hypertension and mortality. We observed positive correlations between serum fetuin-A levels and bone mass in lower limbs, trunk, gynoid region and whole-body. Considering 